(C) 2011 IEEE. Personal use of this material is permitted. Permission from IEEE must be obtained for all other uses, in any current or future media, including reprinting/republishing this material for advertising or promotional purposes, creating new collective works, for resale or redistribution to servers or lists, or reuse of any copyrighted component of this work in other works. 


\title{
Grid Synchronization of DFIG Using Model Predictive Direct Power Control
}

\author{
Yongchang Zhang*†, Zhengxi $\mathrm{Li}^{*}$, Wei $\mathrm{Xu}^{\dagger}$, Jiefeng $\mathrm{Hu}^{\dagger}$, Jianguo $\mathrm{Zhu}^{\dagger}$ \\ *Inverter Technologies Engineering Research Center of Beijing, North China University of Technology, Beijing, China \\ ${ }^{\dagger}$ Faculty of Engineering and Information Technology, University of Technology Sydney, NSW 2007, Australia \\ Email: yozhang@ieee.org
}

\begin{abstract}
This paper presents a model based predictive direct power control (MPDPC) strategy to achieve soft and fast grid synchronization of doubly fed induction generator (DFIG) applied in wind energy applications. The future behavior of active and reactive powers is predicted in MPDPC using the discrete model of DFIG and the most appropriate voltage vector is selected to minimize the errors between the reference value and feedback value of active/reactive powers. Furthermore, the PI regulator and current loop in the existing methods are eliminated, featuring low complexity. The grid connection process is very quick and smooth without any overcurrent. The developed novel MPDPC is compared with prior method based on switching-table-based DPC (STDPC) and shows quicker response, better steady state performance and lower switching frequency, which are validated by the simulation results obtained from a $15 \mathrm{~kW}$ DFIG system.
\end{abstract}

\section{INTRODUCTION}

Due to the pressure of increased consumption of limited fossil fuel resources, renewable source energy has been developed rapidly over the last few decades. Many countries have settled the aim of $20 \%$ portion of renewable energy in the electric power generation [1]. Among various renewable resources, wind power plays a dominant role in the penetration of renewable energy into the grid and it may have an important impact on the power system. As a result, various grid code requirements have been defined to assure safe integration of wind power into the grid without affecting the stability and quality of power systems [2]. Generally, the grid codes require that the modern wind farms behave like conventional power plant, such as flexible active/reactive power regulation, voltage and frequency control, and the capability of keeping connected to the grid and even providing reactive power support when there is a fault (e.g. voltage sags) in the grid. Such requirements means that the wind generator must be able to connect to the grid quickly with minimal impacts on both grid and generators, especially when the fault is cleared.

Various strategies have been proposed for the control of DFIG and the most popular approach is vector control (VC), which is naturally derived from the control of induction machine. In VC, the rotor current is decomposed into torque (active power) and rotor flux (reactive power) components in the synchronous stator flux frame and they are regulated separately using linear controller such as PI [3]. The main drawback of VC is that its controller design relies heavily on the machine parameters and requires appropriate decoupling and much tuning work to ensure the system performance over the entire operating range [4].

Recently, direct control methods, including direct torque control (DTC) [5] and direct power control (DPC) [6], were proposed for the control of DFIG. The PI regulators in VC are eliminated and replaced by hysteresis comparators. A predefined switching table is used to select the most suitable rotor voltage vector to restrict the errors between the reference value and the feedback value. In DPC/DTC, very quick response is obtained with very simple control structure and the tuning work is much reduced compared to VC. However, variable switching frequency and relatively poor steady state performance are the two most notable drawbacks of DTC/DTC [7]. There have been some improvements of conventional DTC/DPC, including using multilevel inverter [8], using two [9] or three vectors [10] during one control period and space vector modulation (SVM) based method [11], etc. Although better performance were obtained, generally the complexity of these methods is also increased.

DTC/DPC is different from VC in that it takes the discrete nature of power converter into account and considers the generator and converter from a system view. As a result, its principle is simple and straightforward and eliminates the multi-loop structure in VC. However, the effectiveness of the switching table is questionable, because the voltage drop across the resistance is neglected during the establishment of the switching table. Consequently, the vector selected from the predefined switching table may not be the best one from the view of ripple reduction. A more complete and accurate approach is model predictive control (MPC), which considers the complete model of power converter and generator without any omission [12]. Furthermore, the future behavior of the system is predicted with the help of the discrete model, so better performance can be anticipated in MPC [13], [14].

Despite the numerous papers on DFIG, they are mostly related to the control of DFIG under grid-connected operation. There are only a few papers addressing the grid synchronization process before connecting DFIG to the grid and they are mostly based on VC [15]-[18]. Traditional method uses cascaded structure and four PI regulators to achieve grid synchronization, with two PIs in the outer voltage loop to minimize the voltage differences and two PIs in the inner rotor current control [16]. The structure can be simplified by eliminating the inner current loop and the number of PIs is reduced to half [17]. Another method uses the current loop 
only and two PIs are needed [15]. The robustness to voltage disturbance can be improved by replacing PIs in [17] with integral variable structure controller (IVSC) [18]. However, the parameters of IVSC still need to be carefully selected. Although smooth connection is achieved using the methods above, the dynamic response is not very satisfactory and can be further improved.

Recently direct control methods have also been extended to the grid synchronization process of DFIG, including STDTC [19], [20] and STDPC [21], [22]. The method in [20] requires three PIs and the information of rotor position, rotor current and both stator voltage and grid voltage measurement. The PI regulators and grid voltage measurement are eliminated in [19] by introducing the concept of virtual torque, so the complexity is reduced compared to [20]. In the methods above, switching table is still used except [22]. Better performance will be obtained if the switching table in DTC/DPC is replaced by MPC. In fact, the MPC has been combined with DTC in the grid synchronization process and achieves quicker response and less ripples in [13]. This paper will further extend MPC to the grid synchronization based on DPC [21], which is called model predictive direct power control (MPDPC) in this paper. The superiority of MPDPC over conventional STDPC will be confirmed by simulation results.

\section{STDPC OF DFIG IN GRID-Connected Mode}

\section{A. Model of DFIG}

The model of DFIG described using complex vectors in an arbitrary frame with a rotating speed of $\omega_{k}$ can be expressed as:

- Voltage equations:

$$
\begin{aligned}
& \boldsymbol{u}_{s}=R_{s} \boldsymbol{i}_{s}+\frac{d \boldsymbol{\psi}_{s}}{d t}+j \omega_{k} \boldsymbol{\psi}_{s} \\
& \boldsymbol{u}_{r}=R_{r} \boldsymbol{i}_{r}+\frac{d \boldsymbol{\psi}_{r}}{d t}+j\left(\omega_{k}-\omega_{r}\right) \boldsymbol{\psi}_{r}
\end{aligned}
$$

- Flux equations:

$$
\begin{aligned}
\boldsymbol{\psi}_{s} & =L_{s} \boldsymbol{i}_{s}+L_{m} \boldsymbol{i}_{r} \\
\boldsymbol{\psi}_{r} & =L_{m} \boldsymbol{i}_{s}+L_{r} \boldsymbol{i}_{r}
\end{aligned}
$$

- Torque equation:

$$
T_{e}=1.5 p \lambda L_{m} \boldsymbol{\psi}_{r} \otimes \boldsymbol{\psi}_{s}
$$

where $\boldsymbol{u}_{\boldsymbol{s}}, \boldsymbol{i}_{s}, \boldsymbol{u}_{r}, \boldsymbol{i}_{r}, \boldsymbol{\psi}_{s}$ and $\boldsymbol{\psi}_{r}$ are the stator voltage vector, stator current vector, rotor voltage vector, rotor current vector, stator flux linkage vector and rotor flux linkage vector, respectively; $R_{s}, R_{r}, L_{s}, L_{r}$ and $L_{m}$ are the stator resistance, rotor resistance, stator inductance, rotor inductance and mutual inductance, respectively; $\omega_{r}$ and $p$ are the electrical rotor speed and pole pairs and $\lambda=1 /\left(L_{s} L_{r}-L_{m}^{2}\right)$.

From (3) and (4), the stator and rotor current can be expressed by stator and rotor flux as

$$
\begin{aligned}
\boldsymbol{i}_{s} & =\lambda\left(L_{r} \boldsymbol{\psi}_{s}-L_{m} \boldsymbol{\psi}_{r}\right) \\
\boldsymbol{i}_{r} & =\lambda\left(-L_{m} \boldsymbol{\psi}_{s}+L_{s} \boldsymbol{\psi}_{r}\right)
\end{aligned}
$$

where $\lambda=1-L_{m}^{2} /\left(L_{s} L_{r}\right)$.
TABLE I

VECTOR TABLE FOR ACTIVE POWER AND REACTIVE POWER REGULATION

\begin{tabular}{ccc}
\hline$Q$ & $P$ & Selected vector \\
\hline$\uparrow$ & $\uparrow$ & $\boldsymbol{V}_{k-2}$ \\
$\uparrow$ & $\downarrow$ & $\boldsymbol{V}_{k+2}$ \\
$\downarrow$ & $\uparrow$ & $\boldsymbol{V}_{k-1}$ \\
$\downarrow$ & $\downarrow$ & $\boldsymbol{V}_{k+1}$ \\
\hline
\end{tabular}

\section{B. Principle of STDPC}

The complex power vector $S$ in the stator side of DFIG can be expressed as

$$
\boldsymbol{S}=P+j Q=1.5 \boldsymbol{i}_{s}^{*} \boldsymbol{u}_{s}
$$

where "*" is the conjugate operator; $P$ and $Q$ indicates the active power and reactive power, respectively.

If the supplied three-phase voltages are sinusoidal and balanced, by neglecting the stator resistance, the relationship between stator voltage and stator flux at steady state can be obtained from (1) as

$$
\boldsymbol{u}_{s}=j \omega_{g} \psi_{s}
$$

where $\omega_{g}$ is the grid frequency $(\mathrm{rad} / \mathrm{s})$.

Substitute (6) and (9) into (8), the complex power can be expressed in terms of stator flux $\psi_{s}$ and rotor flux $\psi_{r}$ as

$$
\boldsymbol{S}=j \cdot k_{\sigma}\left[L_{r}\left|\boldsymbol{\psi}_{s}\right|^{2}-L_{m}\left(\boldsymbol{\psi}_{r}^{*} \boldsymbol{\psi}_{s}\right)\right]
$$

where $k_{\sigma}=1.5 \lambda \omega_{g}$.

By decomposing (10) into real and imaginary components, we obtain

$$
\begin{aligned}
P & =k_{\sigma} L_{m} \operatorname{Im}\left(\boldsymbol{\psi}_{r}^{*} \boldsymbol{\psi}_{s}\right)=k_{\sigma} L_{m}\left|\boldsymbol{\psi}_{r}\right|\left|\boldsymbol{\psi}_{s}\right| \sin \theta \\
Q & =k_{\sigma}\left[L_{r}\left|\boldsymbol{\psi}_{s}\right|^{2}-L_{m} \operatorname{Re}\left(\boldsymbol{\psi}_{r}^{*} \boldsymbol{\psi}_{s}\right)\right] \\
& =k_{\sigma} L_{r}\left|\boldsymbol{\psi}_{s}\right|\left(\left|\boldsymbol{\psi}_{s}\right|-\frac{L_{m}}{L_{r}}\left|\boldsymbol{\psi}_{r}\right| \cos \theta\right)
\end{aligned}
$$

where $\theta$ is the angle $\boldsymbol{\psi}_{s}$ leading $\boldsymbol{\psi}_{r}$.

Because the stator flux is rotating with constant grid frequency and its amplitude is almost constant, the variations of $P$ and $Q$ depend mainly on the change of $\psi_{r}$, which is controlled by the rotor voltage $\boldsymbol{u}_{r}$. From (11), (12) and (2), the appropriate rotor voltage to achieve desired changes in both $P$ and $Q$ can be summarized in Tab. I, where $k$ is the sector number obtained from the rotor flux position in rotor frame. The selection of rotor voltage in the first sector is illustrated in Fig. 1.

\section{GRID SYNCHRONIZATION USING STDPC}

The dynamic equations of DFIG before connecting to the grid can be derived from (1) to (4) as

$$
\begin{aligned}
\boldsymbol{u}_{s} & =\frac{d \boldsymbol{\psi}_{s}}{d t}+j \omega_{k} \boldsymbol{\psi}_{s} \\
\boldsymbol{u}_{r} & =R_{r} \boldsymbol{i}_{r}+\frac{d \boldsymbol{\psi}_{r}}{d t}+j\left(\omega_{k}-\omega_{r}\right) \boldsymbol{\psi}_{r} \\
\boldsymbol{\psi}_{s} & =L_{m} \boldsymbol{i}_{r} \\
\boldsymbol{\psi}_{r} & =L_{r} \boldsymbol{i}_{r}
\end{aligned}
$$




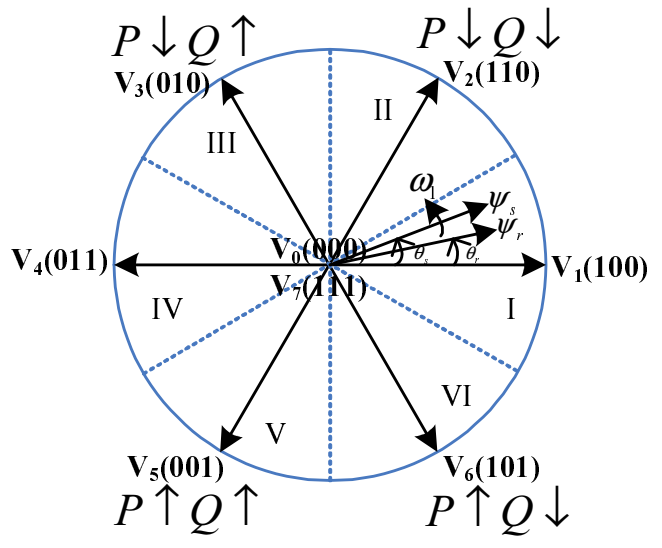

Fig. 1. Sector division for DPC of DFIG in rotor frame.

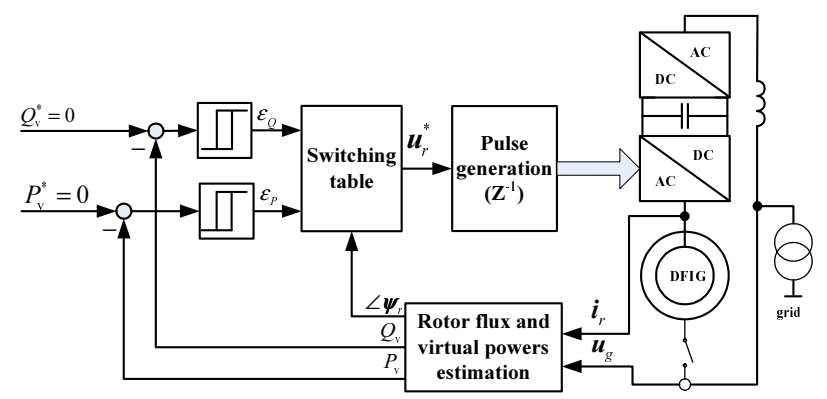

Fig. 2. Control diagram of DFIG grid synchronization using STDPC.

due to the open stator terminal $\left(\boldsymbol{i}_{s}=0\right)$.

To achieve grid synchronization, the induced stator voltage $\boldsymbol{u}_{s}$ must be the same as the grid voltage $\boldsymbol{u}_{g}$ in terms of voltage amplitude, frequency and phase angle. This can be achieved by controlling their integrations to be equal, i.e. $\psi_{s}=\psi_{g}$, where $\int \boldsymbol{u}_{s} d t=\boldsymbol{\psi}_{s}$ and $\int \boldsymbol{u}_{g} d t=\boldsymbol{\psi}_{g}$. Considering (15) and (16), the final requirement for achieving grid synchronization is

$$
\psi_{r}=\frac{L_{r}}{L_{m}} \boldsymbol{\psi}_{g}
$$

According to (14), satisfying (17) is realized by controlling rotor voltage $\boldsymbol{u}_{r}$. There are various ways to generate the desired $\boldsymbol{u}_{r}$. However, it would be more interesting and useful to incorporate the grid synchronization in grid-connected DPC seamlessly. To achieve grid synchronization in the frame of DPC, a virtual complex power is defined as

$$
\boldsymbol{S}_{v}=j \cdot k_{\sigma}\left[L_{r}\left|\boldsymbol{\psi}_{g}\right|^{2}-L_{m}\left(\boldsymbol{\psi}_{r}^{*} \boldsymbol{\psi}_{g}\right)\right]
$$

which is obtained by simply replacing the stator flux $\psi_{s}$ in (10) by grid flux $\boldsymbol{\psi}_{g}$. Due to the similarity of $\boldsymbol{\psi}_{g}$ and $\boldsymbol{\psi}_{s}$, the switching table in Tab. I obtained in grid-connected model will still be valid for the process of grid synchronization [21].

Considering the grid synchronization requirement in (17), the reference value of $\boldsymbol{S}_{v}$ can be obtained as $\boldsymbol{S}_{v}^{\text {ref }}=0$ by substituting (17) into (18). The whole diagram of grid synchronization using STDPC is illustrated in Fig. 2.

\section{GRID SYNCHRONIZATION USING MPDPC}

\section{A. Basic Principle}

As introduced in Section I, the vector selected from conventional STDPC may be not the best one in reducing the error between the reference value and feedback value. Sometimes the vector may be incorrect due to the simplification of model when deriving the switching table. Different from STDPC, the vector selection in MPDPC is not based on a predefined switching table, but based on the on-line evaluation of the influence of each possible rotor voltage vector [13]. MPDPC would be more accurate and effective than STDPC because it takes the complete model of DFIG and converter into account without any omissions. Generally, the voltage vector minimizing the power error $\left|\boldsymbol{S}_{v}^{r e f}-\boldsymbol{S}_{v}\right|$ at the end of next instant will be selected. However, the voltage selection principle can also be extended to incorporate other nonlinear constraints due to its flexibility, such as switching frequency reduction [14].

According to the grid synchronization principle in Section III, the best rotor voltage vector should minimize the following cost function

$$
\begin{aligned}
\min . & \left|\boldsymbol{S}_{v}^{k+1}\right| \\
& =\left|j \cdot k_{\sigma}\left[L_{r}\left|\boldsymbol{\psi}_{g}^{k+1}\right|^{2}-L_{m}\left(\left(\boldsymbol{\psi}_{r}^{k+1}\right)^{*} \boldsymbol{\psi}_{g}^{k+1}\right)\right]\right| \\
\text { s.t. } & \boldsymbol{u}_{r}^{k} \in\left\{\mathbf{V}_{0}, \mathbf{V}_{1}, \ldots \mathbf{V}_{6}, \mathbf{V}_{7}\right\}
\end{aligned}
$$

where $k+1$ means the $(k+1) t h$ instant. It should be noted that if a null vector is selected, the specific state $\left(\mathbf{V}_{0}(000)\right.$ or $\mathbf{V}_{7}(111)$ ) will be decided according to the switching states of the old voltage vector to achieve minimum switching commutations.

For sinusoidal balanced grid voltage, we have $d \boldsymbol{u}_{g} / d t=$ $j \omega_{g} \boldsymbol{u}_{g}$, so the grid flux $\boldsymbol{\psi}_{g}^{k+1}$ can be obtained from the grid voltage $\boldsymbol{u}_{g}^{k+1}$ as

$$
\boldsymbol{\psi}_{g}^{k+1}=\boldsymbol{u}_{g}^{k+1} /\left(j \omega_{g}\right)
$$

where $\boldsymbol{u}_{g}^{k+1}=\boldsymbol{u}_{g}^{k}+j \omega_{g} \boldsymbol{u}_{g}^{k}$.

The rotor flux $\boldsymbol{\psi}_{r}^{k+1}$ in (19) can be obtained from (14) and (16) under the rotor frame as:

$$
\boldsymbol{\psi}_{r}^{k+1}=L_{r}\left[\boldsymbol{i}_{r}^{k}+\frac{T_{s}}{L_{r}}\left(\boldsymbol{u}_{r}^{k}-R_{r} \boldsymbol{i}_{r}^{k}\right)\right]
$$

where $T_{s}$ is the control period.

\section{B. Digital Delay Compensation}

It is well known that there is one-step delay in digital implementation. In other word, the voltage vector decided at the $k$ th instant will not be applied until the $(k+1) t h$ instant [14]. To eliminate this delay, the value at $(k+2) t h$ instant should be used in (19) rather than $(k+1) t h$ instant, which requires a two-step prediction [13]. As a result, the cost function in (19) should be changed to

$$
\begin{aligned}
\min . & \left|\boldsymbol{S}_{v}^{k+2}\right| \\
& =\left|j \cdot k_{\sigma}\left[L_{r}\left|\boldsymbol{\psi}_{g}^{k+2}\right|^{2}-L_{m}\left(\left(\boldsymbol{\psi}_{r}^{k+2}\right)^{*} \boldsymbol{\psi}_{g}^{k+2}\right)\right]\right| \\
\text { s.t. } & \boldsymbol{u}_{r}^{k+1} \in\left\{\mathbf{V}_{0}, \mathbf{V}_{1}, \ldots \mathbf{V}_{6}, \mathbf{V}_{7}\right\}
\end{aligned}
$$




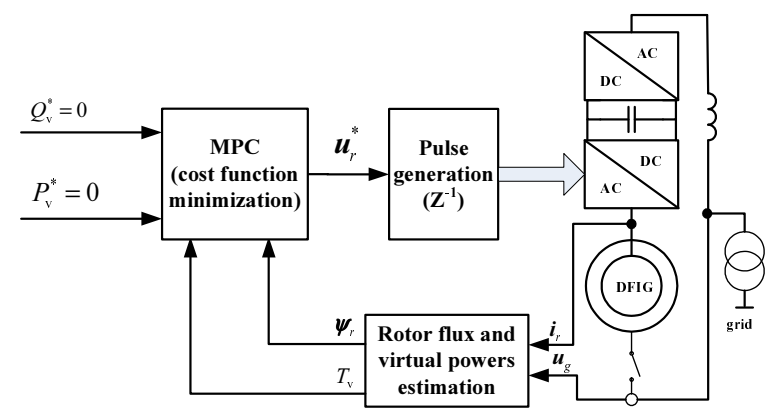

Fig. 3. Control diagram of DFIG grid synchronization using MPDPC.

TABLE II

CONTROL AND MACHINE PARAMETERS

\begin{tabular}{lcr}
\hline DC-bus voltage [V] & $V_{d c}$ & 500 \\
Rated motor power [kW] & $P_{N}$ & 15 \\
Rated motor voltage [V] & $U_{N}$ & 380 \\
Rated (Based) motor frequency [Hz] & $f_{N}$ & 50 \\
Number of motor pairs & $N_{p}$ & 2 \\
Motor stator resistance $[\Omega]$ & $R_{s}$ & 0.168 \\
Motor rotor resistance $[\Omega]$ & $R_{r}$ & 0.199 \\
Motor mutual inductance $[\mathrm{H}]$ & $L_{m}$ & 0.050 \\
Motor stator inductance $[\mathrm{H}]$ & $L_{s}$ & 0.050 \\
Motor rotor inductance $[\mathrm{H}]$ & $L_{r}$ & 0.045 \\
\hline
\end{tabular}

where $\boldsymbol{\psi}_{g}^{k+2}$ and $\boldsymbol{\psi}_{r}^{k+2}$ are predicted in a similar way to (20) and (21) and $\boldsymbol{u}_{r}^{k+1}$ is to be decided.

The whole diagram of grid synchronization using MPDPC is illustrated in Fig. 3. It is seen that the hysteresis comparator and switching table in STDPC (Fig. 2) are replaced by the cost function minimization method in (22).

\section{Simulation Results}

To confirm the effectiveness of the proposed MPDPC for grid synchronization, simulations on a $15 \mathrm{~kW}$ DFIG are carried out in the environment of Matlab/Simulink. The machine parameters of DFIG is shown in Tab. II. The sampling frequency is $20 \mathrm{kHz}$ for both STDPC and MPDPC and the hysteresis band width is zero for STDPC. The average switching frequencies for STDPC and MPDPC are $2.76 \mathrm{kHz}$ and $1.98 \mathrm{kHz}$.

\section{A. Responses Before Grid Connection}

Firstly, the responses before connecting to the grid will be presented. Fig. 4 shows the responses of virtual active power, virtual reactive power and rotor current, and Fig. 5 shows the zoomed dynamic responses of stator/grid voltage and stator/grid flux. The test condition is that before $t=0.05$ $\mathrm{s}$, the DFIG has been driven to the speed of $0.8 \mathrm{pu}$ and the dc-link voltage has been established by controlling the gridside converter. The commanding value of virtual powers are zero.

It is seen from Fig. 4 that the virtual active/reactive powers reach their respective commanding value very quickly in both STDPC and MPDPC. The steady state performance of MPDPC is much better than that of STDPC by exhibiting much lower power ripples and less harmonics in the rotor current. The dynamic process is very fast and it takes only about
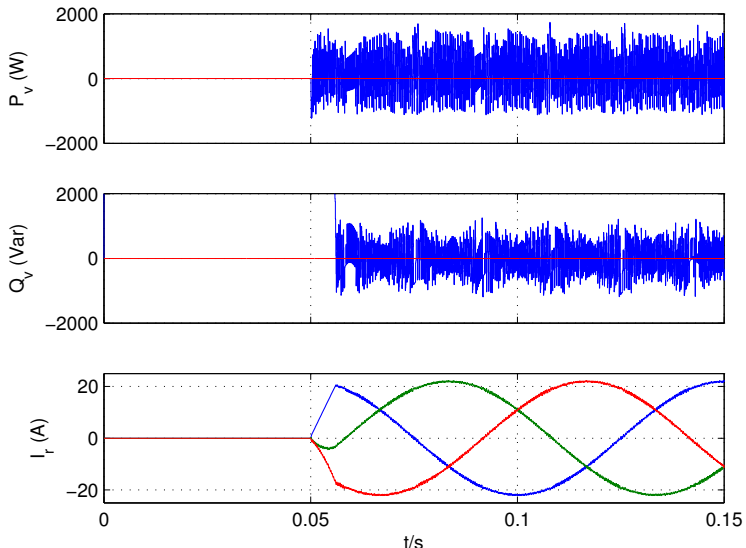

(a)
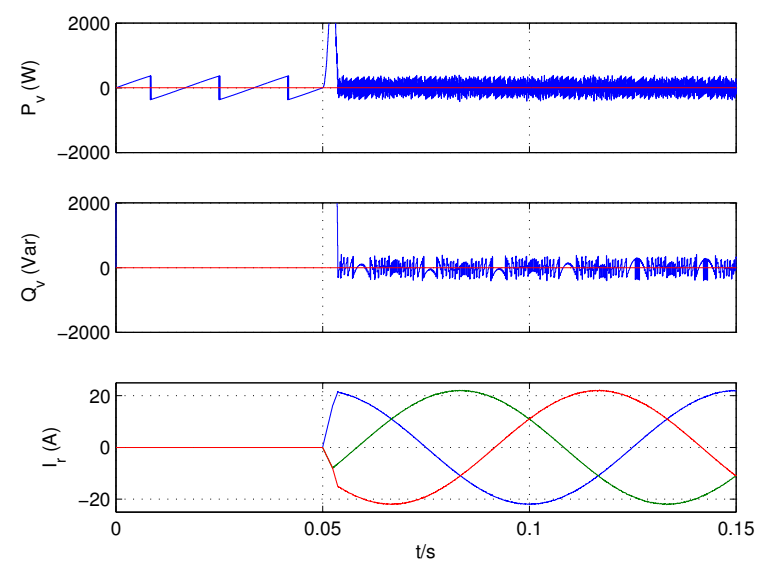

(b)

Fig. 4. Response of virtual active power, reactive power and rotor current before grid connection using (a) STDPC and (b) MPDPC.

3 milliseconds for MPDPC to achieve grid synchronization, as shown in Fig. 5. On the contrary, this value increases to about 5 milliseconds in the case of STDPC, validating the superiority of MPDPC in dynamic performance.

The effectiveness of using the concept of virtual complex power is further confirmed in Fig. 6, where the virtual active power steps from $-0.5 \mathrm{pu}$ rated power to zero at $\mathrm{t}=0.1 \mathrm{~s}$. It is clearly seen that the angle between the grid flux and stator flux can be controlled by the virtual active power. According to (18), the negative value of $P_{v}$ means that the grid flux is lagging the stator flux, which is in accordance to Fig. 6. The angle mismatch between the grid flux and stator flux diminishes immediately, validating the quick response of STDPC and MPDPC. Again much lower power ripples can be observed in MPDPC.

\section{B. Responses During Grid Connection}

Fig. 7 further shows the responses of active power, reactive power, stator currents and rotor currents during the grid connection process for both STDPC and MPDPC. The stator of DFIG is connected to the grid at $t=0.2 \mathrm{~s}$ and the commanding active/reactive powers are still zero. It should 

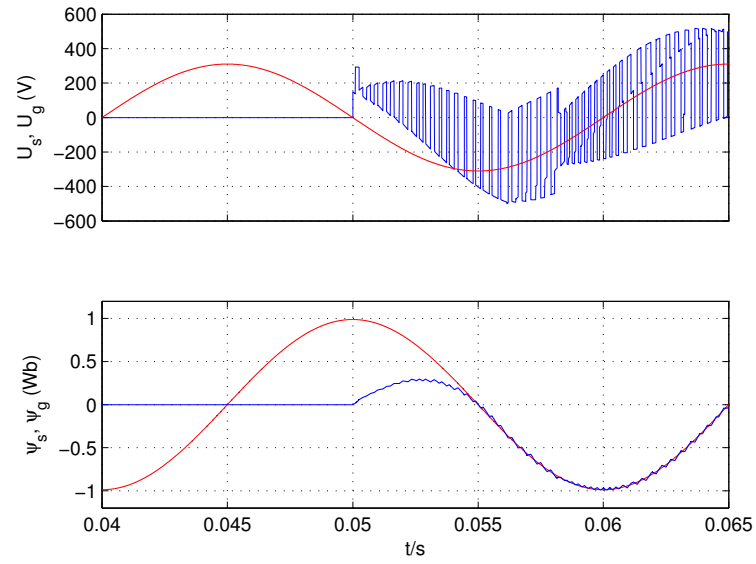

(a)
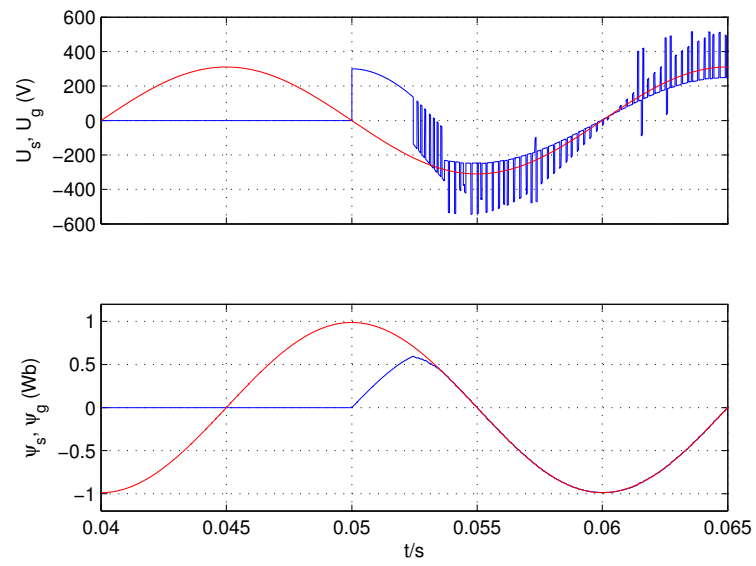

(b)

Fig. 5. Response of stator/grid voltage and stator/grid flux before grid connection using (a) STDPC and (b) MPDPC.

be noted that the feedback active and reactive powers are estimated from the real stator currents and stator voltages using (8) after $\mathrm{t}=0.2 \mathrm{~s}$ and from grid flux and rotor flux using (18) before $\mathrm{t}=0.2 \mathrm{~s}$. It is clear seen that MPDPC presents lower ripples in both active/reactive powers and stator/rotor currents, especially in the grid-connected stage.

The responses of stator/grid voltage and stator/grid flux during this process are shown in Fig. 8. There are almost no changes in the stator and grid flux due to the zero command of active/reactive powers.

\section{CONCLUSiON}

This paper proposes a novel grid synchronization method based on MPDPC and compares it with the conventional STDPC. The high ripples in STDPC caused by switching table and hysteresis comparators are overcome in MPDPC by accurately considering the effects of each rotor voltage vector. A cost function is defined in MPDPC and the voltage vector minimizing the errors between the reference value and the feedback value is selected. By utilizing this predictive method, quicker response and better steady state performance are obtained compared to STDPC. At the same time, the
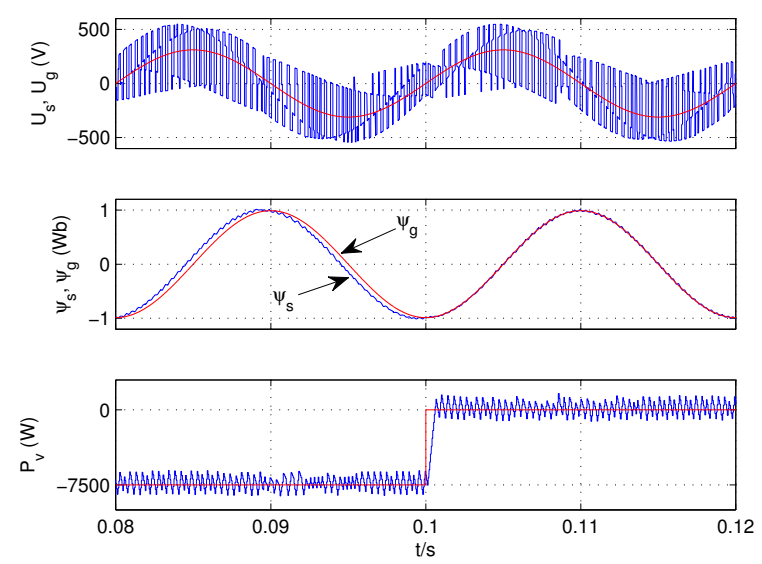

(a)
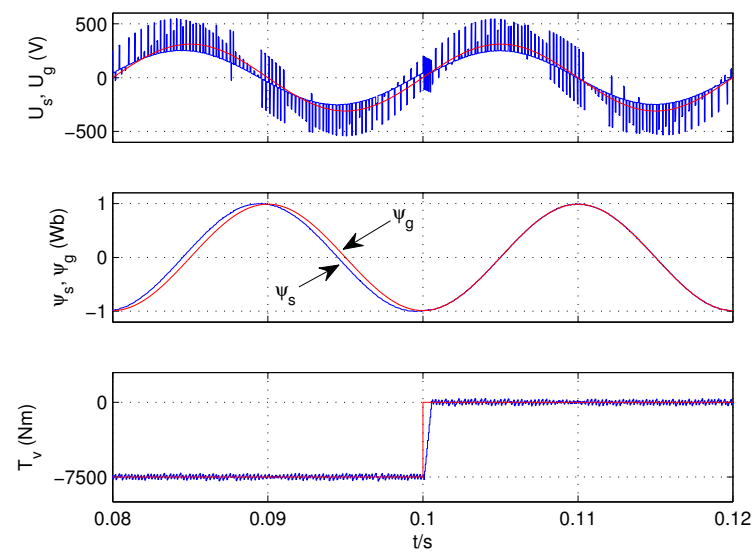

(b)

Fig. 6. Response of stator/grid voltage, stator/grid flux and virtual torque with stepped virtual active power command using (a) STDPC and (b) MPDPC.

average switching frequency is lower under the condition of the same sampling frequency, as shown in the simulation results. Finally, the MPDPC using the concept of virtual complex power is slightly simpler than MPDTC, which uses the concept of virtual torque [13], [19].

\section{REFERENCES}

[1] R. Teodorescu, M. Liserre, and P. Rodríguez, Grid Converters for Photovoltaic and Wind Power Systems. IEEE-Wiley, 2011.

[2] M. Tsili and S. Papathanassiou, "A review of grid code technical requirements for wind farms," IET Renewable Power Generation, vol. 3 , no. 3, pp. 308-332, 2009.

[3] R. Pena, J. C. Clare, and G. M. Asher, "Doubly fed induction generator using back-to-back pwm converters and its application to variable-speed wind-energy generation," IEE Proceedings -Electric Power Applications, vol. 143, no. 3, pp. 231-241, 1996.

[4] Y. Zhang and J. Zhu, "Direct torque control of cascaded brushless doubly fed induction generator for wind energy applications," in Proc. IEEE Int. Electric Machines and Drives Conf. IEMDC '11, 2011, pp. 751-756.

[5] S. Arnalte, J. Burgos, and J. Rodriguez-Amenedo, "Direct torque control of a doubly-fed induction generator for variable speed wind turbines," Electric power components and systems, vol. 30, no. 2, pp. 199-216, 2002.

[6] R. Datta and V. Ranganathan, "Direct power control of grid-connected wound rotor induction machine without rotor position sensors," IEEE Trans. Power Electron., vol. 16, no. 3, pp. 390 -399, may 2001. 

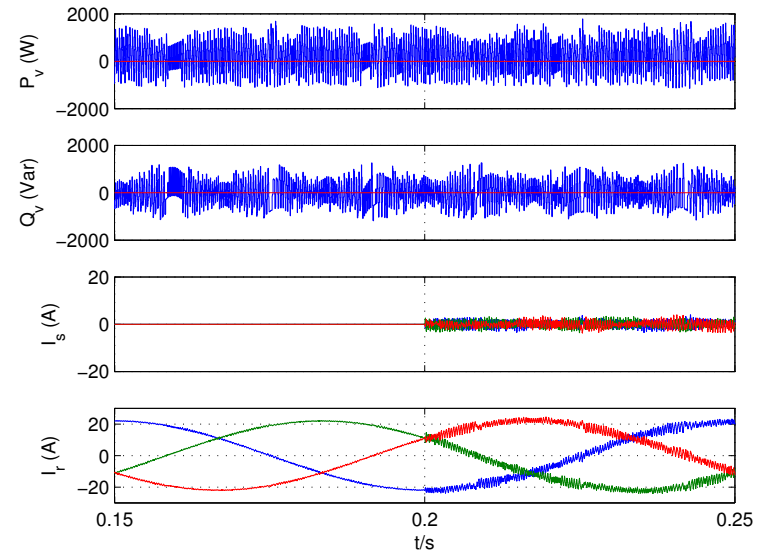

(a)
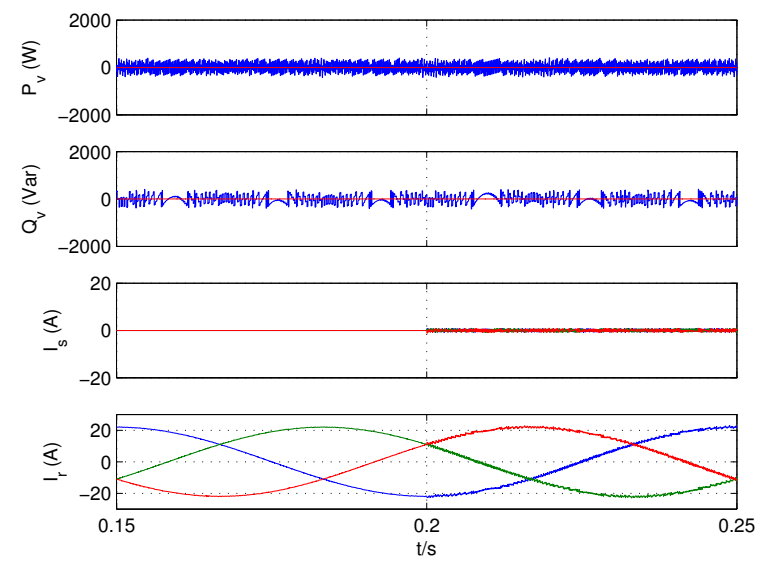

(b)

Fig. 7. Response of active power, reactive power, stator current and rotor current during the grid connection process using (a) STDPC and (b) MPDPC.

[7] Y. Zhang, J. Zhu, and W. Xu, "Analysis of one step delay in direct torque control of permanent magnet synchronous motor and its remedies," in Proc. Int Electrical Machines and Systems (ICEMS) Conf, 2010, pp. $792-797$.

[8] Y. Zhang, J. Zhu, Z. Zhao, W. Xu, and D. G. Drroell, "An improved direct torque control for three-level inverter-fed induction motor sensorless drive," IEEE Trans. Power Electron., vol. 26, pp. 1-12, 2011, in press.

[9] Y. Zhang and J. Zhu, "Direct torque control of permanent magnet synchronous motor with reduced torque ripple and commutation frequency," IEEE Trans. Power Electron., vol. 26, no. 1, pp. 235 -248, 2011.

[10] — - "A novel duty cycle control strategy to reduce both torque and flux ripples for DTC of permanent magnet synchronous motor drives with switching frequency reduction," IEEE Trans. Power Electron., pp. $1-13,2011$, in press.

[11] Y. Zhang, J. Zhu, W. Xu, and Y. Guo, "A simple method to reduce torque ripple in direct torque-controlled permanent-magnet synchronous motor by using vectors with variable amplitude and angle," IEEE Trans. Ind. Electron., vol. 58, no. 7, pp. 2848-2859, 2011.

[12] P. Cortes, M. Kazmierkowski, R. Kennel, D. Quevedo, and J. Rodriguez, "Predictive control in power electronics and drives," IEEE Trans. Ind. Electron., vol. 55, no. 12, pp. $4312-4324$, dec. 2008.

[13] Y. Zhang, J. Zhu, and J. Hu, "Model predictive direct torque control for grid synchronization of doubly fed induction generator," in Proc. IEEE Int. Electric Machines and Drives Conf. IEMDC '11, 2011, pp. 775-780.

[14] Y. Zhang, J. Zhu, and W. Xu, "Predictive torque control of permanent magnet synchronous motor drive with reduced switching frequency," in Proc. Int Electrical Machines and Systems (ICEMS) Conf, 2010, pp.
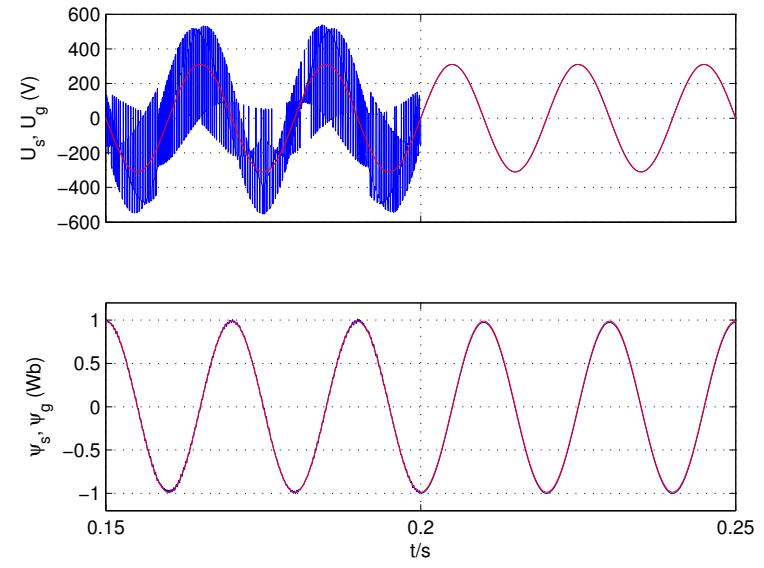

(a)
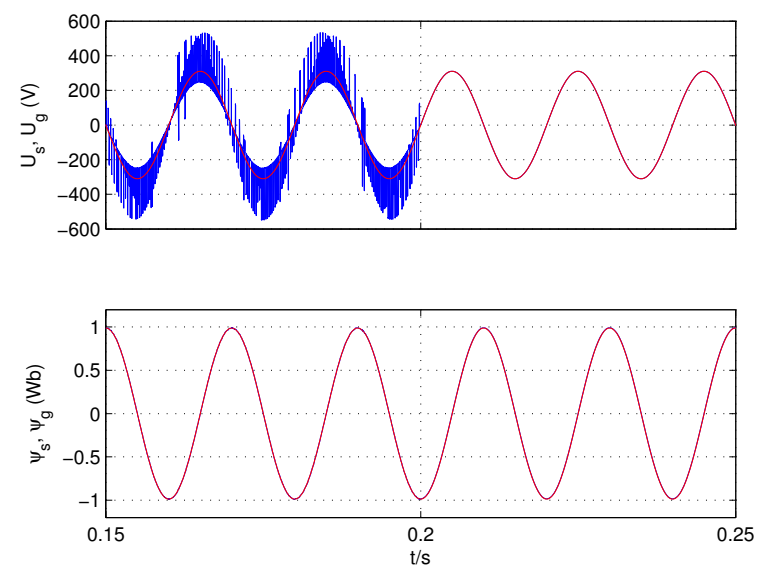

(b)

Fig. 8. Response of stator/grid voltage and stator/grid flux during the grid connection process using (a) STDPC and (b) MPDPC.

798-803.

[15] G. Yuan, J. Chai, and Y. Li, "Vector control and synchronization of doubly fed induction wind generator system," in Proc. 4th Int. Power Electronics and Motion Control Conf. IPEMC 2004, vol. 2, 2004, pp. 886-890.

[16] J. Park, K. Lee, and D. Kim, "Control method of a doubly-fed induction generator with automatic grid synchronization," in Proc. IECON 2006 32nd Annual Conf. IEEE Industrial Electronics, 2006, pp. 4254-4259.

[17] K. Wong, S. Ho, and K. Cheng, "Direct Voltage Control for Grid Synchronization of Doubly-fed Induction Generators," Electric Power Components and Systems, vol. 36, no. 9, pp. 960-976, 2008.

[18] S. Z. Chen, N. C. Cheung, K. C. Wong, and J. Wu, "Grid synchronization of doubly-fed induction generator using integral variable structure control," IEEE Trans. Energy Convers., vol. 24, no. 4, pp. 875-883, 2009.

[19] J. Arbi, M. J.-B. Ghorbal, I. Slama-Belkhodja, and L. Charaabi, "Direct virtual torque control for doubly fed induction generator grid connection," IEEE Trans. Ind. Electron., vol. 56, no. 10, pp. 4163-4173, 2009.

[20] S. A. Gomez and J. L. R. Amenedo, "Grid synchronisation of doubly fed induction generators using direct torque control," in Proc. IEEE 2002 28th Annual Conf IECON 02, vol. 4, 2002, pp. 3338-3343.

[21] J.-B. G. Manel, A. Jihen, and S.-B. Ilhem, "A novel approach of direct active and reactive power control allowing the connection of the dfig to the grid," in Proc. 13th European Conf. Power Electronics and Applications EPE '09, 2009, pp. 1-10.

[22] Y. Lan, S. Xiaoliang, C. Guocheng, and Y. Yan, "Research on idle load grid-connection control strategy for double-fed induction generator (dfig) based on direct power control," in Proc. Int. Conf. Mechatronics and Automation ICMA 2009, 2009, pp. 5014-5018. 